\title{
OURCOAST, A European initiative to support exchange of experiences and best practices in coastal management
}

\author{
Rob Stejin ${ }^{1}$, Alan Pickaver ${ }^{2}$, Maria Ferriera ${ }^{2}$, Patrycja Czerniak ${ }^{2}$, Bernd Heinichen ${ }^{3}$ and Annemie Volckaert ${ }^{4}$ \\ Arcadis-Netherlands/Alkyon Hydraulic Consultancy \& Research, Voorsterweg 28, 8316 PT Markness, The \\ Netherlands; tel;+31 527248111 \\ Coastal \& Marine Union (EUCC), PO box 11232, 2301 EE Leiden, The Netherlands; tel. +31 $715122900 ;$ fax:+31 71 \\ 5124069 email: a.pickaver@eucc.net; m.ferreira@eucc.net; admin@eucc.net \\ Arcadis-Germany, Consult GmBH, IT-Entwicklung, Gluck-Auf-Str, 109599 Freiberg, Germany; Tel +49 (3731) 7887 \\ 44; Fax+49 (3731) 788699 email: b.heinichen@arcadis.de \\ ${ }^{4}$ Arcadis-Belgium, Kortrijksesteenweg 302, B-9000 Gent, Belgium; Tel. +32 924177 31; Fax +32 924244 45, email: \\ a.volckaert@arcadisbelgium.be
}

OURCOAST is a three-year initiative commissioned by the General Directorate (DG) Environment of the European Commission to support and ensure the exchange of experiences and best practices in coastal management. This initiative was made possible thanks to the European Parliament that voted a dedicated resource for this purpose into the EU budget in 2008.

The European Commission has intensively worked on developing and promoting Integrated Coastal Zone Management (ICZM) principles. More recently, an evaluation on ICZM in Europe concluded that although there is still great willingness of Authorities at national, regional and locals levels to implement ICZM, there is still a number of fundamental obstacles that need to be overcome. Some of these constraints are reflected in the lack of proper means for exchange of experiences and access to outstanding studies and best practices being produced in Coastal Member States, at different authority levels.

The overall goal of OURCOAST is to create an information base and groundwork that will further support and promote the implementation of ICZM in coastal areas by the establishment of long-lasting information mechanisms that will promote the sharing of experiences and practices and the accomplishments of the project. The project will produce numerous studies of public interest, such as, a comparative analysis of ICZM and marine planning experiences, a state-of-the-art report on EU policies and legislation for ICZM and marine planning. Guidance for future integrated and marine planning projects, and policy recommendations will be formulated for future development of ICZM in Europe. The final results will be presented at an international stakeholders conference in Autumn 2011.

The OURCOAST initiative aims to establish a multi-lingual database of Europe-wide ICZM practices in the form of case studies that will be freely accessible through the EUROPA European Commission official web-site to the broad coastal and marine communities and to provide practical guidance to all those who are seeking sustainable solutions to their coastal management practices. Following these challenges, this paper aims to provide more insight and details about the progress activities and various components of the OURCOAST initiative, which is being implemented by a consortium led by ARCADIS and it's subcontractor the Coastal \& Marine Union (EUCC). The implementation has started in January 2009 and will end in December 2011. The data collection, website development as well as the analysis are currently being carried out. 